\title{
Recombinant Superoxide Dismutase Reduces Oxygen Free Radical Concentrations in Reperfused Myocardium
}

\author{
Jay L. Zweier, Barry K. Rayburn, John T. Flaherty, and Myron L. Weisfeldt \\ Cardiology Division, Johns Hopkins Medical Institutions, Department of Medicine, Baltimore, Maryland 21205; \\ and the Laboratory of Technical Development, National Heart, Lung, and Blood Institute, Bethesda, Maryland 20892
}

\begin{abstract}
It has been proposed that oxygen free radicals mediate damage that occurs during postischemic reperfusion. Recombinant human superoxide dismutase (r-h-SOD) has been shown to be effective at reducing reperfusion injury, but it is not known if this infused enzyme actually reduces oxygen free radical concentrations in the myocardial tissue. Electron paramagnetic resonance spectroscopy was used to directly measure the effect of $r-h-S O D$ on free radical concentrations in the postischemic heart. Hearts were freeze clamped at $77^{\circ} \mathrm{K}$ after $10 \mathrm{~min}$ of normothermic global ischemia followed by $10 \mathrm{~s}$ of reflow with control perfusate $(n=7)$ or perfusate containing 60,000 $U$ r-h-SOD $(n=7)$. The spectra of these hearts exhibited three different signals: signal $A$ isotropic, $g=2.004$, identical to the carbon-centered ubiquinone free radical; signal $B$ anisotropic with axial symmetry, $\mathrm{g}_{\|}=\mathbf{2 . 0 3 3}, \mathrm{g}_{\perp}=\mathbf{2 . 0 0 5}$, identical to the oxygen-centered alkyl peroxyl free radical; and the signal $\mathrm{C}$ an isotropic triplet, $g=2.000, a_{n}=24 \mathrm{G}$, similar to a nitrogencentered free radical such as a peroxyl amine. With r-h-SOD administration the concentration of the oxygen free radical, signal B, was reduced $49 \%$ from $6.8 \pm 0.3 \mu \mathrm{M}$ to $3.5 \pm 0.3 \mu \mathrm{M}(P$ $<0.01)$ and the concentration of the nitrogen free radical, signal C, was reduced $38 \%$ from $3.4 \pm 0.3$ to $2.1 \pm 0.3 \mu \mathrm{M}(P$ $<0.01)$. The concentration of the carbon-centered free radical, signal A, however, was increased $51 \%$ from $3.3 \pm 0.2$ to $5.0 \pm 0.2$ $\mu \mathrm{M}(\boldsymbol{P}<0.01)$. Identical reperfusion with peroxide-inactivated r-h-SOD did not alter the concentrations of free radicals indicating that the specific enzymatic activity of $r-h-S O D$ is required to decrease the concentrations of reactive oxygen free radicals. Additional measurements performed varying the duration of reflow demonstrate a burst of oxygen free radical generation peaking at $10 \mathrm{~s}$ of reperfusion. r-h-SOD entirely abolished this burst. These studies demonstrate that superoxide-derived free radicals are generated during postischemic reperfusion and suggest that the beneficial effect of $r-h-S O D$ is due to its specific enzymatic scavenging of superoxide free radicals.
\end{abstract}

\section{Introduction}

Spontaneous thrombosis of a coronary artery produces regional myocardial ischemia and ultimately myocardial infarction. It has been demonstrated that timely reperfusion of ischemic myocardium can reduce the amount of necrosis after coronary artery occlusion (1-5). There is evidence, however, that reperfusion while terminating ischemia may also cause further myocardial damage (6-9). This reperfusion damage is

Received for publication 7 April 1987 and in revised form 8 July 1987.

The Journal of Clinical Investigation, Inc.

Volume 80, December 1987, 1728-1734 thought to blunt the potential beneficial effect of postischemic reperfusion.

Reperfusion injury is characterized histologically by the formation of contraction bands in the contractile proteins, calcific granules within mitochondria as well as by cell swelling, and disruption of sarcoplasmic and mitrochondial membranes $(10,11)$. It has been proposed that reactive oxygen free radicals are generated in postischemic myocardium and mediate the observed cell injury. A large number of studies demonstrating the beneficial effects of free radical scavengers have given support to the free radical hypothesis. In particular, numerous laboratories have demonstrated that superoxide dismutase (SOD) ${ }^{1}$ administered during ischemia and after reperfusion significantly reduces reperfusion injury (12-15). Recently, recombinant human copper-zinc superoxide dismutase (r-h-SOD) has become available. Studies performed in our laboratory have demonstrated that $\mathrm{r}-\mathrm{h}-\mathrm{SOD}$ administered only during reperfusion markedly improves functional and metabolic recovery in perfused rabbit hearts subjected to global ischemia (16). With regional ischemia in in vivo dogs we have also demonstrated that $\mathrm{r}-\mathrm{h}-\mathrm{SOD}$ administered during reperfusion decreases infarct size (17). Therefore, there is a large quantity of evidence suggesting that administration of SOD can decrease reperfusion injury.

Copper-zinc SOD is a 32,000-mol wt enzyme made up of two identical subunits, each of which contains one $\mathrm{Cu}^{2+}$ and one $\mathrm{Zn}^{2+}(18)$. It catalyzes the reaction ${ }^{\circ} \mathrm{O}_{2}^{-}+{ }^{\circ} \mathrm{O}_{2}^{-}+2 \mathrm{H}^{+} \rightarrow$ $\mathrm{H}_{2} \mathrm{O}_{2}+\mathrm{O}_{2}$, in which two molecules of superoxide $\left({ }^{\circ} \mathrm{O}_{2}^{-}\right)$react to form hydrogen peroxide $\left(\mathrm{H}_{2} \mathrm{O}_{2}\right)$ and molecular oxygen $\left(\mathrm{O}_{2}\right)$. It is presumed that SOD prevents reperfusion injury by specific enzymatic scavenging of superoxide with the elimination of superoxide-derived free radicals, but this has never been proven.

Recently we have applied electron paramagnetic resonance spectroscopy to directly measure and characterize free radical generation in postischemic myocardium. We have demonstrated that there is a burst of oxygen free radicals generated in the first minute of reperfusion (19). In this study we determine if $\mathrm{r}$-h-SOD actually decreases the concentration of oxygen free radicals in postischemic myocardium. In so doing we determine if superoxide-derived radicals are actually generated and if the beneficial effect of SOD is actually due to its specific activity.

\section{Methods}

Isolated rabbit hearts were perfused by the method of Langendorff at a constant pressure of $80 \mathrm{mmHg}$ with a Krebs-bicarbonate buffered

1. Abbreviations used in this paper: EPR, electron paramagnetic resonance; ${ }^{\circ} \mathrm{O}_{2}^{-}$, superoxide; $\mathrm{r}$-h-SOD, recombinant human superoxide dismutase; SOD, superoxide dismutase. 
perfusate consisting of $117 \mathrm{mM} \mathrm{NaCl}, 24.6 \mathrm{mM} \mathrm{NaHCO}_{3}, 5.9 \mathrm{mM}$ $\mathrm{KCl}, 1.2 \mathrm{mM} \mathrm{MgCl}_{2}, 2.5 \mathrm{mM} \mathrm{CaCl}_{2}, 0.5 \mathrm{mM}$ EDTA, $16.7 \mathrm{mM}$ glucose, which was bubbled with $95 \% \mathrm{O}_{2}-5 \% \mathrm{CO}_{2}$ gas. Hearts were freeze clamped using Wollenberger tongs cooled to $77^{\circ} \mathrm{K}$ after $10 \mathrm{~min}$ of ischemia followed by reflow with control perfusate or perfusate containing r-h-SOD. $60,000 \mathrm{U}$ of $\mathrm{r}-\mathrm{h}-\mathrm{SOD}$ were dissolved in perfusate solution and administered over $10 \mathrm{~s}$. The hearts were then freeze clamped, ground to a fine powder under liquid nitrogen, and the powder transferred to precision electron paramagnetic resonance (EPR) tubes. EPR spectra were then recorded at a temperature of $77^{\circ} \mathrm{K}$ using a Varian E-9 spectrometer. Temperature annealing studies were performed to separate the three observed signals. Each of the component signals have different temperature stability and can be isolated by gradual warming of the sample. On warming the heart sample to $193^{\circ} \mathrm{K}$ for $60 \mathrm{~s}$ one of the original spectral components disappeared (Fig. $1 B$ ). The difference spectrum, $A-B$, shows this component to be a

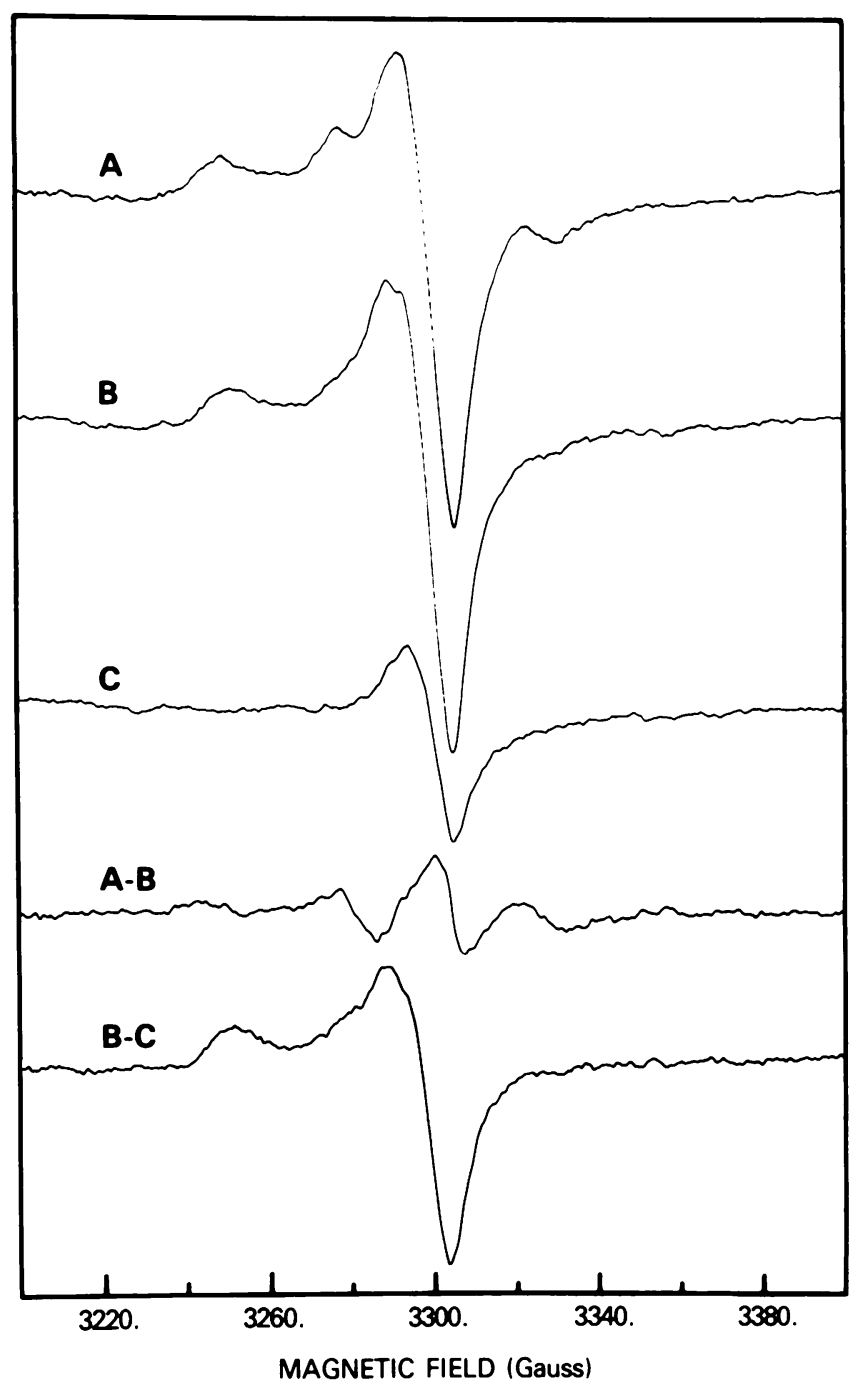

Figure 1. EPR spectra of a heart sample freeze clamped after $10 \mathrm{~min}$ ischemia followed by $10 \mathrm{~s}$ of reflow with perfusate containing inactivated r-h-SOD. Microwave frequency, $9.278 \mathrm{GHz}$; microwave power, $1.0 \mathrm{mw}$; modulation amplitude, $2.5 \mathrm{G}$. $(A)$ Sample maintained at $77^{\circ} \mathrm{K} ;(B)$ raised to $193^{\circ} \mathrm{K}$ for $1 \mathrm{~min} ;(C)$ raised to $193^{\circ} \mathrm{K}$ for $1 \mathrm{~h} .(A-B)$ Subtraction of spectrum B from spectrum A. $(B-C)$ Subtraction of spectrum $C$ from spectrum $B$. This temperature annealing procedure separates the composite spectrum shown in $A$ into its three component signals: Signal A shown in inset $C$; signal B shown in inset $B-C$; signal $C$ shown in inset $A-B$. triplet signal (Fig. $1 A-B$ ). On further warming to $193^{\circ} \mathrm{K}$ for $1 \mathrm{~h}$, a second component disappears leaving only one remaining component, a symmetric gaussian line (Fig. $1 C$ ). The difference spectra, $B-C$, reveals a signal that exhibits the characteristic absorption function of an electron in an environment with axial symmetry (Fig. $1 B-C$ ). Quantitation of each signal was performed from the ratio of the double integral to that of a known concentration potassium peroxylamine disulfonate standard in frozen aqueous solution in an identical EPR tube (20). Care was taken to perform these measurements with nonsaturating microwave power.

r-h-SOD was obtained from Biotechnology General Corp. and was verified to be $>99 \%$ pure by electrophoresis. Enzymatic inactivation of $\mathrm{r}$-h-SOD was performed by incubation of the enzyme at alkaline $\mathrm{pH}$ with hydrogen peroxide as described by Hodgson and Fridovich (21). This inactivation procedure specifically destroys enzyme activity without altering the protein conformation (21).

\section{Results}

Hearts reflowed for $10 \mathrm{~s}$ with control perfusate or with perfusate containing inactivated $\mathrm{r}-\mathrm{h}-\mathrm{SOD}$ exhibit a well-defined EPR spectrum consisting of three component signals (Fig. 1 $A$ ). The three component signals are $\mathrm{A}$, a symmetric gaussian line at $\mathrm{g}=2.004$ indicative of an isotropic free radical (Fig. 1 $C$ ); $\mathrm{B}$, a signal with axial symmetry $\mathrm{g}_{\|}=2.033, \mathrm{~g}_{\perp}=2.005$ (Fig. $1 B-C$ ), and $C$, a triplet signal with $\mathrm{g}=2.000$ and hyperfine splitting $\mathrm{a}_{\mathrm{n}}=24 \mathrm{G}$ (Fig. $1 A-B$ ).

When samples were thawed at room temperature for 10 min and then refrozen the magnitude of the signals in the $g=2$ region greatly decreased. The $\mathrm{B}$ and $\mathrm{C}$ signals totally disappeared and the A signal decreased by $70 \%$. This confirms that all three observed signals are due to free radicals. Even when spectra were recorded with increased modulation amplitudes of 5 gauss and microwave power of $20 \mathrm{~mW}$, no superimposed signals from paramagnetic metal ions were observed.

Signal A exhibits identical g value, linewidth, power saturation, and temperature stability to that of a semiquinone free radical $(22,23)$. This signal, which is observed in control hearts, appears to correspond to the signal arising from the one electron reduced ubiquinone free radical, which has been previously noted in cells and mitochondrial suspensions (24). Power saturation studies were performed in control heart samples that exhibit the A signal, and the saturation behavior was found to be similar to that of the ubiquinone free radical. At microwave power $>1.0 \mathrm{~mW}$ saturation was observed. The intensity of this signal was stable at $193^{\circ} \mathrm{K}$.

Signal B, which exhibits axial symmetry, is similar to signals previously reported for oxygen-centered free radicals. The observed $g$ values are identical to those of alkyl peroxyl free radicals but also fall within the range of values described for superoxide $(25,26)$. The power saturation behavior of this signal was investigated in samples from postischemic reflowed hearts, and saturation was observed only at high microwave power $>20 \mathrm{~mW}$. This signal was observed to be stable only at very low temperatures $<193^{\circ} \mathrm{K}$. Similar power saturation and temperature instability has been observed for the superoxide anion free radical and the alkyl peroxyl free radical $(25,26)$.

Signal $C$ is a triplet which is suggestive of a nitrogen-centered free radical. This signal is similar to that of the frozen peroxylamine standard, but the identity of this free radical remains uncertain.

It has previously been shown that signal $\mathrm{A}$ is observed in the normally perfused heart, whereas signals $B$ and $C$ appear 
during ischemia and markedly increase in the early seconds of postischemic reperfusion (19). Identical spectra were observed from hearts reflowed with control perfusate or perfusate containing inactivated $r-h-S O D$. Hearts reflowed with perfusate containing enzymatically active r-h-SOD, however, exhibited clearly different spectra than the control or inactivated $r-h-$ SOD-treated hearts. The total signal was reduced with marked changes observed in each of the three component signals. As can be seen on careful examination of these spectra, each of the component signals were variably affected (Fig. 2). With the temperature annealing technique previously described, each of the three component signals were resolved.

The oxygen centered radical, signal $\mathrm{B}$, is clearly decreased by treatment with enzymaticly active r-h-SOD (Fig. 3). The nitrogen-centered radical is also decreased with administration of active r-h-SOD, as seen in Fig. 4. However, the relatively stable carbon-centered free radical is increased with active $r-h-$ SOD treatment (Fig. 5).

Hearts were subjected to $10 \mathrm{~min}$ of ischemia followed by reflow for $10 \mathrm{~s}$ with either control perfusate or perfusate containing r-h-SOD, with seven hearts in each group. EPR spectra were obtained and then resolved into the component signals. In each of the hearts similar changes were observed to those previously noted above (Figs. 3-5). Each of the component signals were quantitated by double integration and comparison to the double integral of the peroxylamine standard. The oxygen-centered free radical, signal $\mathrm{B}$, was decreased from a concentration of $6.8 \pm 0.3$ to $3.5 \pm 0.3 \mu \mathrm{M}$, whereas the nitrogen-centered free radical, signal $C$, was decreased from $3.4 \pm 0.3$ to $2.1 \pm 0.3 \mu \mathrm{M}$. The carbon-centered free radical, signal A, was

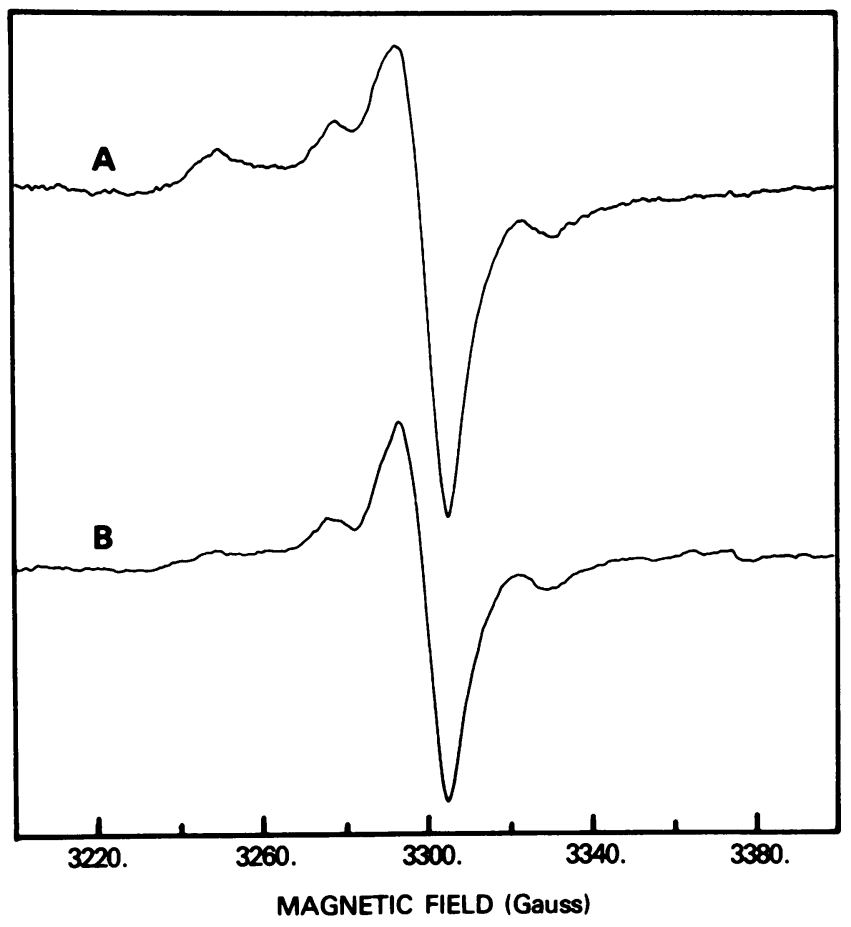

Figure 2. EPR spectra of a heart sample free clamped after $10 \mathrm{~min}$ ischemia followed by $10 \mathrm{~s}$ of reflow with perfusate containing either inactivated r-h-SOD $(A)$ or active r-h-SOD $(B)$. Both spectra were obtained with identical instrument settings at $77^{\circ} \mathrm{K}$. Microwave frequency, $9.278 \mathrm{GHz}$; microwave power, $1.0 \mathrm{mw}$; modulation amplitude, $2.5 \mathrm{G}$.

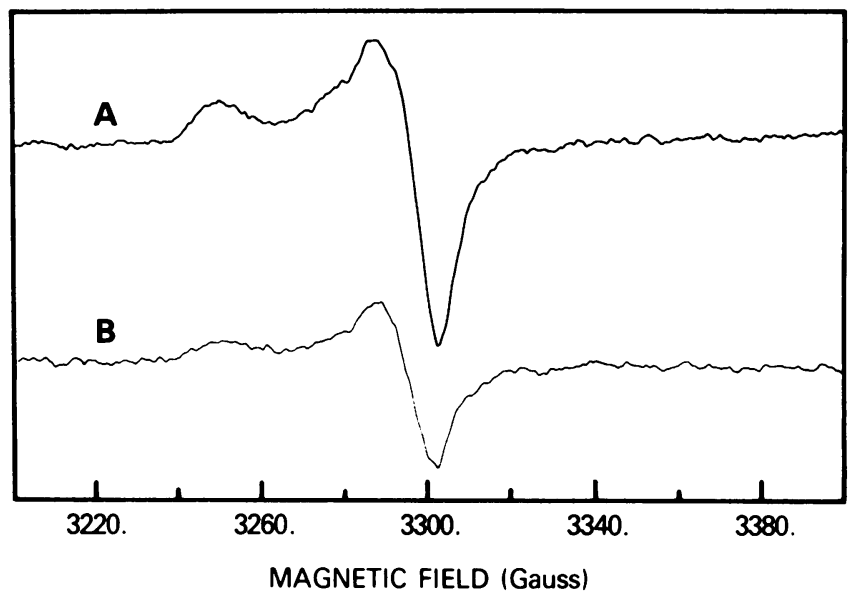

Figure 3. Effect of r-h-SOD on the oxygen free radical, signal B. Spectra were obtained by subjecting the samples from Fig. 2 to the temperature annealing procedure shown in Fig. 1. $(A)$ Reflowed with inactivated r-h-SOD; $(B)$ reflowed with active r-h-SOD.

increased from a concentration of $3.3 \pm 0.2$ to $5.0 \pm 0.2 \mu \mathrm{M}$. Statistical analysis demonstrated that each of the changes were significant with $P<0.01$.

To assess whether the observed effect of r-h-SOD represents a true decrease in oxygen-free radical generation rather than just a temporal shift in the peak of free radical generation, we reperfused hearts after $10 \mathrm{~min}$ ischemia for varying lengths of time ranging from 1 to $60 \mathrm{~s}$. As shown in Fig. $6 a$, when hearts are reflowed with control perfusate there is a burst of oxygen free radical generation with levels peaking at $10 \mathrm{~s}$ of reflow. r-h-SOD administered almost totally eliminated this burst in oxygen free radical generation throughout this period of reperfusion. With r-h-SOD treatment the concentration of the oxygen-centered free radical, signal $B$, did not significantly increase above the level observed during ischemia (Fig. $6 a$ ). Similarly these time course experiments demonstrate that with $\mathrm{r}$-h-SOD treatment there is a true increase in the overshoot of the carbon-centered free radical, signal A, which occurs after reperfusion (Fig. 6 b).

\section{Discussion}

Over the last decade a large body of evidence has accumulated, indicating that reperfusion of ischemic myocardium, though beneficial, is accompanied by specific reperfusion injury (6-9).

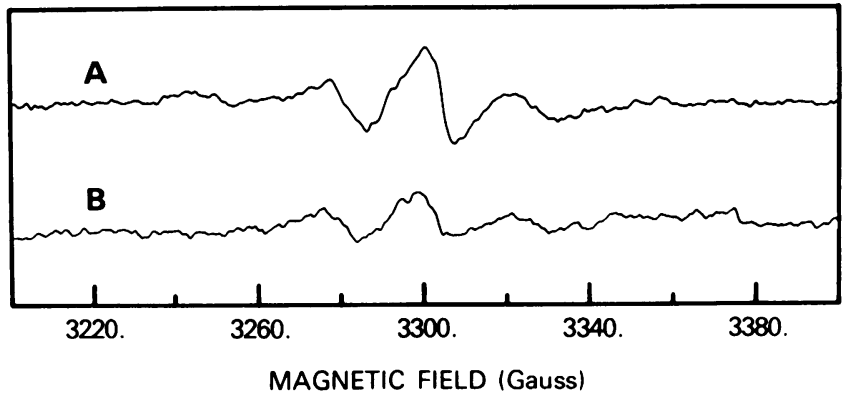

Figure 4. Effect of r-h-SOD on the component nitrogen free radical, signal C. Spectra were obtained by subjecting the samples from Fig. 2 to the temperature annealing procedure shown in Fig. 1. (A) Reflowed with inactivated $\mathrm{r}-\mathrm{h}-\mathrm{SOD} ;(B)$ reflowed with active r-h-SOD. 


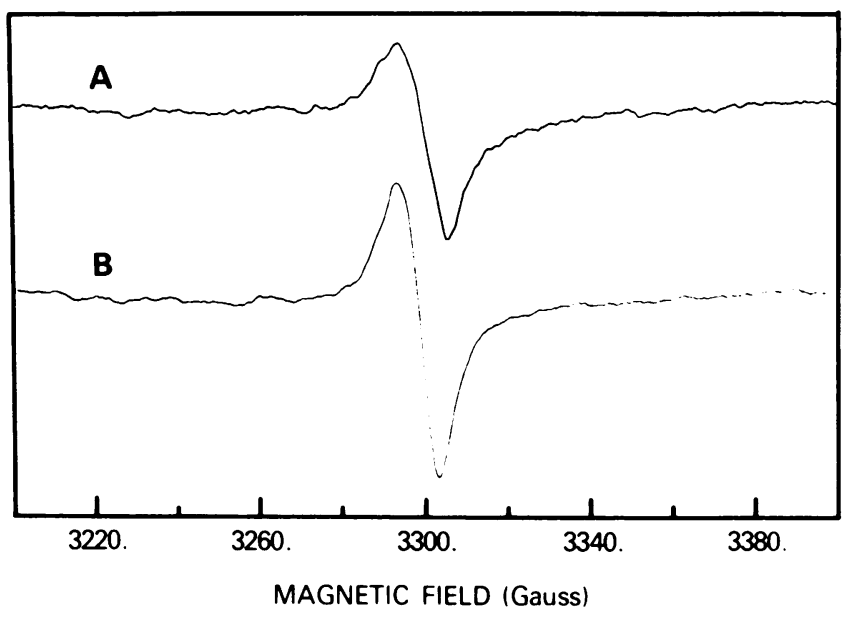

Figure 5. Effect of r-h-SOD on the component carbon free radical, signal A. Spectra were obtained by subjecting the samples from Fig. 2 to the temperature annealing procedure shown in Fig. 1. $(A) \mathrm{Re}-$ flowed with inactivated $\mathrm{r}$-h-SOD; $(B)$ reflowed with active r-h-SOD.

It has been postulated that oxygen free radicals generated during postischemic reperfusion are responsible for much of this reperfusion injury. It has been specifically proposed that during ischemia and postischemic reperfusion that large quantities of superoxide free radicals, $\mathrm{O}_{2}^{-}$, are generated (12-16). This ${ }^{\circ} \mathrm{O}_{2}^{-}$can react to form the more reactive hydroxyl radical, $\cdot \mathrm{OH}$, via the iron-catalyzed Fenton and Haber-Weiss reactions as shown in Eqs. 1 and 2:

$$
\begin{aligned}
\mathrm{O}_{2}^{-}+\mathrm{Fe}^{3+} & \rightarrow \mathrm{Fe}^{2+}+\mathrm{O}_{2}, \\
\mathrm{Fe}^{2+}+\mathrm{H}_{2} \mathrm{O}_{2} & \rightarrow \mathrm{Fe}^{3+}+\mathrm{OH}^{-}+{ }^{\circ} \mathrm{OH} .
\end{aligned}
$$

The ${ }^{\circ} \mathrm{OH}$ which is generated will in turn react with biological molecules such as lipid membranes attacking unsaturated fatty acid chains, resulting in lipid peroxidation and the formation of lipid alkyl peroxyl radicals, ROO', as shown in Eqs. 3-5:

$$
\begin{aligned}
\mathrm{R}-\mathrm{H}+{ }^{\circ} \mathrm{OH} & \rightarrow \mathrm{H}_{2} \mathrm{O}+\mathbf{R}^{\cdot} \\
\mathbf{R}^{*}+\mathrm{O}_{2} & \rightarrow \mathrm{ROO}^{\circ} \\
\mathbf{R}-\mathrm{H}^{+} \mathrm{ROO}^{\circ} & \rightarrow \mathrm{ROOH}+\mathbf{R}^{*} .
\end{aligned}
$$

Thus, lipid peroxidation once initiated by ${ }^{\circ} \mathrm{OH}$ can be self perpetuated. This process may be the cause of the membrane abnormalities and cell swelling observed in reperfused myocardium.

The free radical hypothesis has been supported by a number of animal model studies showing that administration of the superoxide radical scavenging enzyme, SOD, during postischemic reperfusion results in greater recovery of myocardial function and smaller infarct size (12-14). Jolly et al. (13), Werns et al. (14), and Chambers et al. (15) have demonstrated that bovine SOD significantly reduces infarct size in a canine model of regional myocardial ischemia and reperfusion. Protective effects have been noted with several other free radical scavengers as well (27-30). Thus, there is considerable indirect evidence supporting the free radical hypothesis of reperfusion injury. Recently, we have directly demonstrated using electron paramagnetic resonance spectroscopy that large concentrations of oxygen free radicals are actually generated during postischemic reperfusion (19).

As a result of recombinant DNA technology the human copper-zinc enzyme, r-h-SOD, is now available. This enzyme fully retains it enzymatic activity and only differs from the naturally occuring human red blood cell SOD in that its amino-terminus is not acetylated. Studies in the isolated rabbit heart model of global ischemia and the canine model of re-
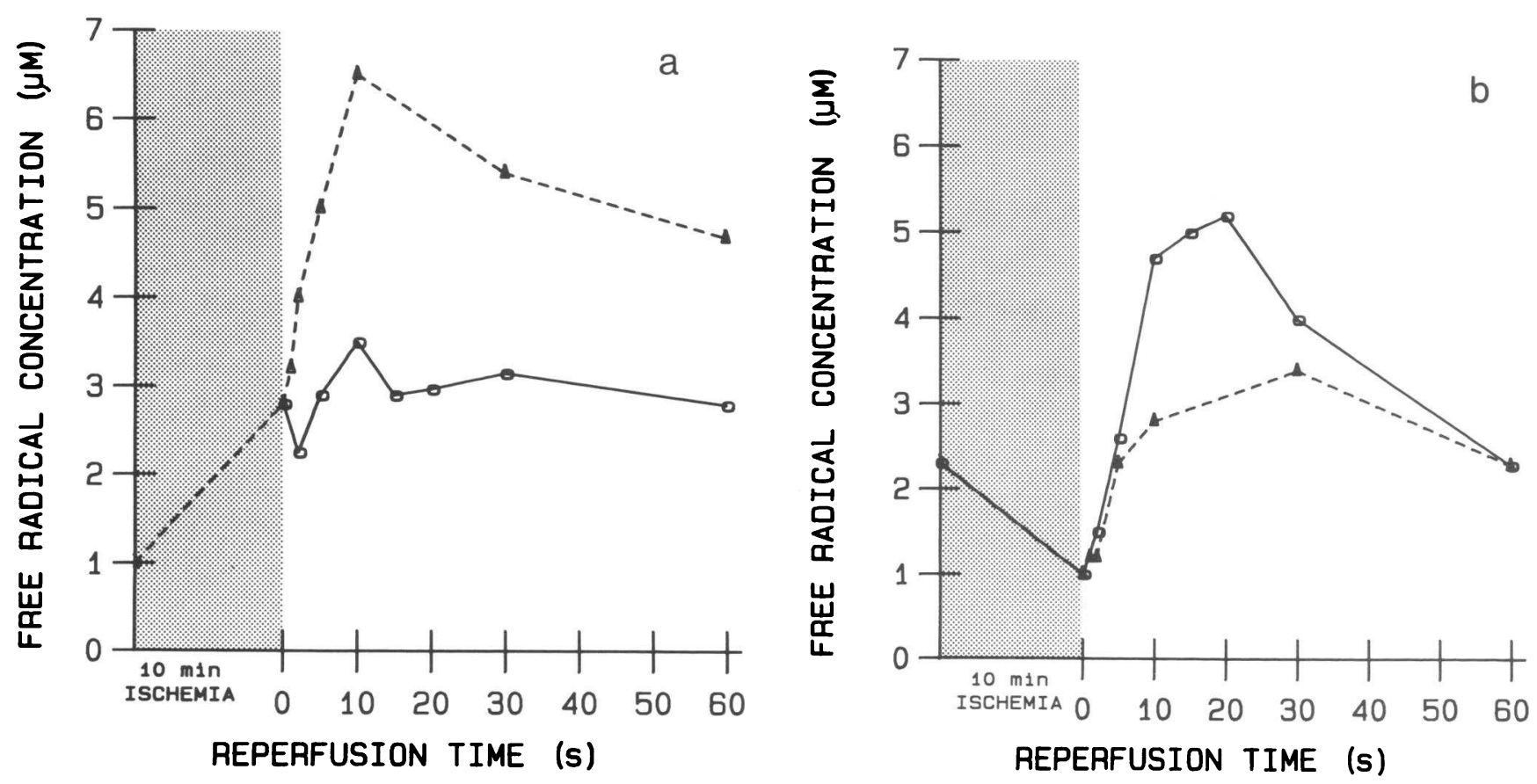

Figure 6. Time course of free radical generation in hearts reflowed with and without r-h-SOD. Each point corresponds to measurements performed on hearts freeze clamped at different points in time. $\Delta$ Reflow with control perfusate, $O$ reflow with active r-h-SOD. (a) Time course of the oxygen-centered free radical signal, signal B. (b) Time course of the carbon centered free radical, Signal A. 
gional ischemia have demonstrated that r-h-SOD treatment during reperfusion can result in improved recovery of function and high energy phosphates as well as reduction in infarct size $(15,16)$.

Based on these previous studies it has been presumed that r-h-SOD reduces reperfusion injury via its specific enzymatic scavenging of superoxide free radical, however, this has never been proven. In addition, it has been presumed that large quantities of superoxide-derived free radicals are generated in reperfused myocardium. In this study we have directly measured and characterized the free radicals generated in postischemic myocardium using EPR spectroscopy. Three distinct EPR signals were observed. Two of these signals were from highly reactive temperature labile free radicals. One of these labile signals, signal B, was anisotropic with axial symmetry with $g_{\|}=2.033$ and $g_{\perp}=2.005$. The $g$ values, temperature instability, and power saturation properties of this signal are identical to those previously demonstrated for the alkyl peroxyl free radical, $\mathrm{ROO}^{\circ}(25)$. The presence of axial symmetry is also similarly observed for the superoxide free radical, ${ }^{\circ} \mathrm{O}_{2}^{-}$, however, the observed $\mathrm{g}$ values are different than those reported for $\mathrm{O}_{2}^{-}$in aqueous solution. A broad range of $\mathrm{g}$ values have been reported for ${ }^{\circ} \mathrm{O}_{2}^{-}$depending on the solvent and the $\mathrm{pH}$ (26). The observed $\mathrm{g}$ values of signal $\mathrm{B}$ fall within the range of possible $\mathrm{g}$ values. However, the observed values are clearly different from the values of $\mathrm{g}_{\|}=2.08$ and $\mathrm{g}_{\perp}=2.001$ noted for $\mathrm{O}_{2}^{-}$formed by the aqueous xanthine oxidase or $\mathrm{H}_{2} \mathrm{O}_{2}-\mathrm{NaIO}_{4}$ generating systems. Therefore, this signal appears to be secondary to the alkyl peroxyl free radical derived from ${ }^{\circ} \mathrm{O}_{2}^{-}$rather than ${ }^{\circ} \mathrm{O}_{2}^{-}$itself.

The other temperature labile free radical exhibits a triplet signal with a $g$ value of 2.000 and hyperfine splitting $a_{n}=24 \mathrm{G}$. The presence of this triplet splitting suggests coupling of the electron to a nucleus with nuclear spin, $I=1$. The only such biologically available nucleus is nitrogen so it is presumed that this signal arises from a nitrogen-centered free radical. The exact identity of this free radical is unclear, but the $g$ value and observed hyperfine splitting is similar to that seen with the peroxyl amine disulfonate standard. This free radical could possibly arise from the reaction of ${ }^{\circ} \mathrm{OH}$ with protein amines resulting in the formation of peroxyl amine derivatives.

The third signal arises from a much less reactive and relatively temperature-stable free radical. This signal is isotropic with a $g$ value of 2.004 . The observed $g$ value, linewidth, temperature stability, and power saturation behavior of the signal are identical to those of the one electron reduced ubiquinone free radical observed in mitochondrial suspensions associated with normal respiration, which results in electron transport through co-enzyme $Q(24)$. This signal is observed in normally perfused hearts; it falls during ischemia and then briefly rises above the baseline levels after reperfusion. In contrast to the two temperature labile signals which disappear on warming to $193^{\circ} \mathrm{K}$, this signal is stable at $193^{\circ} \mathrm{K}$ and is still observed even after thawing at room temperature.

Reperfusion of hearts with r-h-SOD markedly changed the concentrations of each of these free radicals. The reactive oxygen centered alkyl peroxyl free radical was reduced $49 \%$ from a peak concentration of 6.8 to $3.5 \mu \mathrm{M}$, whereas the reactive nitrogen radical concentration was reduced $38 \%$ from 3.4 to $2.1 \mu \mathrm{M}$. The stable carbon-centered ubiquinone free radical, however, was increased $51 \%$ from 3.3 to $5.0 \mu \mathrm{M}$. Reperfusion of $\mathrm{r}-\mathrm{h}-\mathrm{SOD}$, which was inactivated by prior hydrogen peroxide treatment, did not alter the free radical concentrations. In experiments performed varying the duration of reperfusion, it was observed that $r-h-S O D$ treatment eliminated the burst of oxygen free radical generation observed with postischemic reperfusion.

These observations demonstrate that superoxide free radicals are generated in postischemic myocardium and react with biological molecules to form alkyl peroxyl free radicals. This process would be expected to potentially result in cellular damage with resultant impaired contractile function. Indeed, we have previously observed in the same rabbit global ischemia model that there is reperfusion-induced functional and metabolic impairment that can be prevented with r-h-SOD (16). $\mathrm{r}$-h-SOD administered during postischemic reperfusion markedly decreased the concentration of reactive oxygen free radicals in postischemic myocardium and eliminated the burst of oxygen free radical generation that occurs with postischemic reperfusion. Interestingly, the stable carbon-centered free radical, which appears to be the one electron reduced ubiquinone free radical, is increased with SOD treatment. In the absence of r-h-SOD treatment an overshoot above baseline concentrations was observed during the first minute of reperfusion, however, with $\mathrm{r}-\mathrm{h}-\mathrm{SOD}$ treatment this overshoot is exaggerated. This exaggerated overshoot in the ubiquinone free radical concentration could be secondary to improved and more rapid metabolic recovery with resultant increased rates of electron transport funneling electrons through ubiquinone. Previous phosphorus nuclear magnetic resonance studies have demonstrated that $r-h-S O D$ treatment does result in an improved and more rapid metabolic recovery, and a similar exaggerated overshoot in the phosphocreatine concentration was observed (15). In addition the conversion of ${ }^{\circ} \mathrm{O}_{2}^{-}$to $\mathrm{O}_{2}$ by r-h-SOD could increase tissue $\mathrm{O}_{2}$ content with increased electron transport resulting in a more marked overshoot in the concentration of the one electron reduced ubiquinone free radical.

A number of mechanisms have been proposed to generate ${ }^{\circ} \mathrm{O}_{2}^{-}$in postischemic myocardium. During ischemia high concentrations of hypoxanthine accumulate due to the degradation of ATP (31). Metabolism of this nucleotide is normally mediated by xanthine dehydrogenase; during ischemia however, this enzyme is converted to the oxidase form which reduces $\mathrm{O}_{2}$ forming ${ }^{\circ} \mathrm{O}_{2}^{-}$(32). Other possible sources of ${ }^{\circ} \mathrm{O}_{2}^{-}$include mitochondrial oxidation (33), oxidation of catecholamines released locally during ischemia (34), and generation by polymorphonuclear leukocytes that migrate to the ischemic tissue (35). Another potentially important mechanism of ${ }^{\circ} \mathrm{O}_{2}^{-}$ formation is the oxidation of heme proteins. In particular, the conversion of oxy-myoglobin and oxy-hemoglobin from the ferrous to the ferric redox state could result in the formation of large quantities of ${ }^{\circ} \mathrm{O}_{2}^{-}$. It is well known that acidic conditions induce the conversion of native ferrous myoglobin or hemoglobin to the ferric met-state (36). During global ischemia it has been demonstrated that marked myocardial acidosis occurs (16). Therefore ischemia could also prime this mechanism of ${ }^{\circ} \mathrm{O}_{2}^{-}$generation, leading to a burst in free radical generation upon reperfusion.

In the non-blood-perfused heart model that we have studied, it is unlikely that sufficient numbers of polymorphonuclear leukocytes would remain to account for the observed oxygen radical formation. However, in vivo, primary myocardial-generated free radicals could activate these leukocytes, resulting in further free radical generation amplifying that seen 
in our model. Therefore leukocyte activation may still be of great importance for in vivo reperfusion injury as previously suggested $(37,38)$. It has also been demonstrated that the concentrations of xanthine oxidase in rabbit myocardium are quite low, as is also the case in man (39). Therefore xanthine oxidase might not be the major source of ${ }^{\circ} \mathrm{O}_{2}^{-}$in our model. Clearly, much further work is needed to define and quantitate the actual mechanisms of ${ }^{\circ} \mathrm{O}_{2}^{-}$generation in reperfused myocardium.

It has been questioned whether a large intravascularly administered macromolecule such as SOD can actually work to decrease myocardial oxygen free radical concentrations. There are three possible ways in which SOD could be working. First, the cell membrance of the ischemic myocyte may become more permeable, allowing SOD to enter the myocyte. Release of the macromolecules creatine kinase and phosphorylase has recently been demonstrated to occur from ischemic myocytes in the absence of cell necrosis $(40,41)$. Alternatively, SOD could be restricted to the vascular space with the ${ }^{\circ} \mathrm{O}_{2}^{-}$generated in the myocytes being transferred to the vascular space. At the low $\mathrm{pH}$ present in ischemic myocardium a significant fraction of the ${ }^{\circ} \mathrm{O}_{2}^{-}$would be protonated and thus able to passively diffuse through the cell membrane to the vascular space. In addition it has been suggested that ${ }^{\circ} \mathrm{O}_{2}^{-}$, even in the ionized state, can be transported out of cells via membrane anion channels (42). Finally, it is possible that ${ }^{\circ} \mathrm{O}_{2}^{-}$could be generated in the vascular space via polymorphonuclear leukocytes or endothelial cells.

In conclusion we have demonstrated that $\mathrm{r}$-h-SOD actually reduces the concentration of ${ }^{\circ} \mathrm{O}_{2}^{-}$-derived free radicals in reperfused myocardium. This effect was only observed with the enzymatically active protein. These observations confirm that $\mathrm{O}_{2}^{-}$is actually generated in reperfused myocardium and suggest that the beneficial effect of r-h-SOD is actually due to the specific enzymatic scavenging of the superoxide free radical.

\section{Acknowledgments}

This work was supported by an Ischemic Heart Disease Specialized Center of Research grant No. HL 17655-13 from the National Heart, Lung and Blood Institute.

\section{References}

1. Costantini, C., E. Corday, T. Lang, S. Meerbaum, J. Brasch, L. Kaplan, S. Rubins, H. Gold, and J. Osher. 1975. Revascularization after 3 hours of coronary arterial occlusion: effects on regional cardiac metabolic function and infarct size. Am. J. Cardiol. 36:368-384.

2. Reimer, K. A., J. E. Lowe, M. M. Rasmussen, and R. B. Jennings. 1977. The wavefront phenomenon of ischemic cell death. I. Myocardial infarct size vs. duration of coronary occlusion in dogs. Circulation 56:786-794.

3. Reimer, K. A., and R. B. Jennings. 1979. The "wavefront phenomenon" of myocardial ischemic cell death. II. Transmural progression of necrosis within the framework of ischemic bed size (myocardium at risk) and collateral flow. Lab. Invest. 40:633-644.

4. Jennings, R. B., and K. A. Reimer. 1983. Factors involved in salvaging ischemic myocardium: effect of reperfusion of arterial blood. Circulation. 68(Suppl. I):25-36.

5. Schaper, J., and W. Schaper. 1983. Reperfusion of ischemic myocardium: ultrastructural and histochemical aspects. J. Am. Coll. Cardiol. 1:1037-1046.

6. Bresnahan, G. F., R. Roberts, W. E. Shell, J. Ross, Jr., and B. E.
Sobel. 1974. Deleterious effects due to hemorrhage after myocardial reperfusion. Am. J. Cardiol. 33:82-86.

7. Frame, L. H., J. A. Lopez, B. A. Khaw, J. T. Fallon, E. Haber, and W. J. Powell, Jr. 1983. Early membrane damage during coronary reperfusion in dogs. Dectection by radiolabeled anticardiac myosin $\left(\mathrm{Fab}^{\prime}\right)_{2}$. J. Clin. Invest. 72:535-544.

8. Bulkley, B. H., and G. M. Hutchins. 1977. Myocardial consequences of coronary artery bypass graft surgery. The paradox of necrosis in areas of revascularization. Circulation. 56:906-913.

9. Montoya, A., J. Mulet, R. Pifarre, G. Brynjolfsson, J. M. Moran, H. J. Sullivan, and R. M. Gunnar. 1978. Hemorrhagic infarction following myocardial revascularization. J. Thorac. Cardiovasc. Surg. 75:206-212.

10. Whalen, D. A., D. G. Hamilton, C. E. Ganote, and R. B. Jennings. 1974. Effective of a transient period of ischemia on my myocardial cells. I. Effects on cell volume regulation. Am. J. Pathol. 74:381-398.

11. Kloner, R. A., C. E. Ganote, D. A. Whalen, and R. B. Jennings. 1974. Effect of a transient period of ischemia on myocardial cells. II. Fine structure during the first few minutes of reflow. Am. J. Pathol. 74:399-422.

12. Shlafer, M., P. F. Kane, and M. M. Kirsh. 1982. Superoxide dismutase plus catalase enhances the efficacy of hypothermic cardioplegia to protect the globally ischemic reperfused heart. J. Thorac. Cardiovasc. Surg. 83:830-839.

13. Jolly, S. R., W. J. Kane, M. B. Bailie, G. D. Abrams, and B. R. Lucchesi. 1984. Canine myocardial reperfusion injury. Its reduction by the combined administration of superoxide dismutase and catalase. Circ. Res. 54:277-285.

14. Werns, S. W., M. J. Shea, E. M. Driscoll, C. Cohen, G. D. Abrams, B. Pitt, and B. R. Lucchesi. 1985. The independent effects of oxygen radical scavengers on canine infarct size. Reduction by superoxide dismutase but not catalase. Circ. Res. 56:895-898.

15. Chambers, D. E., D. A. Parks, G. Patterson, R. Roy, J. M. McCord, S. Yashida, L. F. Parmley, and J. M. Downey. 1985. Xanthine oxidase as a source of free radical damage in myocardial ischemia. 145-152.

16. Ambrosio, G., M. L. Weisfeldt, W. E. Jacobus, and J. T. Flaherty. 1987. Evidence for a reversible oxygen radical-mediated component of reperfusion injury: reduction by recombinant human superoxide dismutase administered at the time of reflow. Circulation. 75:282291.

17. Ambrosio, G., L. C. Becker, G. M. Hutchins, H. F. Weisman, and M. L. Weisfeldt. 1986. Reduction in experimental infarct size by recombinant human superoxide dismutase: insights into the pathophysiology of reperfusion injury. Circulation. 74:1424-1433.

18. Fridovich, I. 1975. Superoxide dismutases. Annu. Rev. Biochem. 44:147-159.

19. Zweier, J. L., J. T. Flaherty, and M. L. Weisfeldt. 1987. Observation of free radical generation in the post-ischemic heart. Proc. Natl. Acad. Sci. USA. In press.

20. Wertz, J. E., and J. R. Bolton. 1972. Electron Spin Resonance. McGraw-Hill Book Co., New York. 192-221.

21. Hodgson, E. K., and I. Fridovich. 1975. The interaction of bovine erythrocyte superoxide dismutase with hydrogen peroxide: inactivation of the enzyme. Biochemistry. 14:5294-5303.

22. Zweier, J. L. 1985. Iron mediated formation of an oxidized adriamycin free radical. Biochim. Biophys. Acta. 839:209-213.

23. Gianni, L., J. L. Zweier, A. Levy, and C. E. Meyers. 1985. Characterization of the cycle of iron-mediated electron transfer from adriamycin to molecular oxygen. J. Biol. Chem. 260:6820-6826.

24. Onishi, T., and B. Trumpower. 1980. Differential effects of antimycin on ubisemiquinone bound in different environments in isolated succinate cytochrome $\mathrm{C}$ reductase complex. J. Biol. Chem. 255:3278-3284.

25. Copeland, E. S. 1975. Th organosulfur peroxy radical in biological systems: an ESR study using an aminothid model system. J. Mag. Res. 20:124-129. 
26. Knowles, P. F., J. F. Gibson, F. M. Pick, and R. C. Bray. 1969. Electron-spin-resonance evidence for enzymatic reduction of oxygen to a free radical, the superoxide ion. Biochem. J. 111:53-58.

27: Hess, M. L., E. Okabe, J. Poland, M. Warner, J. R. Stewart, and Z. J. Greenfield. 1983. Glucose, insulin, potassium protection during the course of hypothermic global ischemia and reperfusion: a new proposed mechanism by the scavenging of free radicals. J. Cardiovasc. Pharmacol. 5:35-43.

28. Lucas, S. K., T. J. Gardner, J. T. Flaherty, B. H. Bulkley, E. B. Elmer, and V. L. Gott. 1980. Beneficial effects of mannitol administration during reperfusion after cardiac arrest. Circulation. 62(Suppl. I):34-41.

29. Nakamura, Y., M. Takahashi, J. Hayashi, H. Mori, S. Ogawa, Y. Tanabe, and H. Hara. 1982. Protection of ischemic myocardium with coenzyme Q10. Cardiovasc. Res. 16:132-137.

30. Shlafer, M., P. F. Kane, and M. Kirsh. 1982. Effects of dimethyl sulfoxide on the globally ischemic heart: possible general relevance to hypothermic organ preservation. Cryobiology. 19:61-69.

31. Jennings, R. B., K. A. Reimer, M. L. Hill, and S. E. Mayer. 1981. Total ischemia in dog hearts in vitro. I. Comparison of high energy phosphate production, utilization and depletion, and of adenine nucleotide catabolism in total ischemia in vitro vs. severe ischemia in vivo. Circ. Res. 49:892-900.

32. McCord, J. M. 1985. Oxygen-deprived free radicals in postischemic tissue injury. N. Engl. J. Med. 312:159-163.

33. Boveris, A., and E. Cadenas. 1975. Mitochondrial production of superoxide and its relationship to the antimycin insensitive respiration. FEBS (Fed. Eur. Biochem. Soc.) Lett. 54:311-314.

34. Singal, P. K., K. S. Kapur, R. E. Dhillon, and N. S. Dhalla. 1982. Role of free radicals in catecholamine-induced cardiomyopathy. Can. J. Physiol. Pharmacol. 60:1390-1397.
35. Fantone, J. C., and P. A. Ward. 1982. Role of oxygen-derived free radicals and metabolites in leukocyte-dependent inflammatory reactions. Am. J. Pathol. 107:397-418.

36. Harrison, S. C., and E. R. Blout. 1965. Reversible conformational changes of myoglobin and apomyoglobin. J. Biol. Chem. 240:299-303.

37. Mullane, K. M., N. Read, S. A. Salmon, and S. Moncada. 1984. Role of leukocytes in acute myocardial infarction in anesthetized dogs: relationship to myocardial salvage by anti-inflammatory drugs. $J$. Pharmacol. Exp. Ther. 228:510-522.

38. Mitsos, S. E., T. E. Askew, J. C. Fanton, S. L. Kunkel, G. D. Abrams, A. Schork, and B. R. Lucchesi. 1986. Protective effects of $\mathrm{N}$-2-mercaptopropionyl glycine against myocardial reperfusion injury after neutrophil depletion in the dog: evidence for the role of intracellular-derived free radicals. Circulation. 73:1077-1086.

39. Khalidi, U. A. S., and T. H. Chaglassian. 1965. The species distribution of xanthine oxidase. Biochem. J. 97:318-320.

40. Michale, L. H., J. R. Hunt, D. Weilbaecher, M. B. Perryman, R. Roberts, R. M. Lewis, and M. L. Entman. 1985. Creatine kinase and phosphorylase in cardiac lymph: coronary occlusion and reperfusion. Am. J. Physiol. 248:H350-H359.

41. Heyndrickx, G. R., J. Amano, T. Kenna, J. T. Fallon, and T. A. Patrick, W. T. Manders, G. G. Rogers, C. Rosendorff, and S. F. Vatner. 1985. Creatine kinase release not associated with myocardial necrosis after short periods of coronary artery occlusion in conscious baboons. J. Am. Coll. Cardiol. 6:1299-1303.

42. Kontos, H. A., E. P. Wei, E. F. Ellis, L. W. Jenkins, J. T. Povlishock, G. T. Rowe, and M. L. Hess. 1985. Appearance of superoxide anion radical in cerebral extracellular space during increased prostaglandin synthesis in cats. Circ. Res. 57:142-151. 